\title{
Parish nursing: Providing spiritual, physical, and emotional care in a small community parish
}

\author{
Susan T Roberts \\ MiraCosta College, Oceanside, CA, U.S.A. \\ Correspondence: Susan T Roberts. Address: One Barnard Drive, Oceanside, CA, U.S.A. Email: sroberts@miracosta.edu \\ Received: January 15, 2014 \\ Accepted: February 27, 2014 \\ Online Published: March 19, 2014 \\ DOI : $10.5430 / c n s . v 2 n 2 p 118$ \\ URL: http://dx.doi.org/10.5430/cns.v2n2p118
}

\section{Abstract}

A health ministry council of parish nurses was established at a small community church to provide holistic health care to its members. The parish nurses work with the lead pastor and committees with its focus on wellness through health counseling, screenings, education, and referrals. Parish nurses' spiritual comfort of congregation members during illness and end-of-life is addressed. The organization of a health ministries council of parish nurses along with the defined role of the parish nurse is identified.

\section{Key words}

Parish nurse, Holistic health care, Spiritual comfort, End-of-life

\section{I ntroduction}

Parish nurses promote health and wellness through holistic nursing care to faith community members and the community at large across the life span. Modern-day parish nursing is a specialized practice wherein nurses partner with members of the parish to focus on healing by addressing the spiritual, physical and emotional health needs of clients within the environment of the faith community ${ }^{[4]}$; in other words, holistic nursing care. The American Holistic Nurses Association articulates the goal of holistic nursing is "to treat and heal the whole person by recognizing the interconnectedness of body, mind, spirit and environment” ${ }^{[1]}$. The health ministry council of parish nurses at Westminster Presbyterian church has established a mission that guides nurses in their roles to enhance the quality of life and wellness for all age groups. The mission is to promote wellness through education, follow-up and counseling. Nurses screen blood pressure, nutrition and blood sugar. Wellness is accomplished through personal spiritual and health counseling, health education, health screenings, patient advocacy, follow-up and referral. The ministry also addresses end-of-life issues and follows up with members who have experienced death and loss and consoles those who are going through the grieving process. This paper describes parish nursing as a specialized practice, outlining holistic care, the roles of the parish nurses, the organization of the health ministries council and the benefits of parish nursing at Westminster Presbyterian Church (WPC). It outlines examples of how a health ministries council is established and organized, and works collaboratively with the lead pastor, staff and parishioners.

\section{Holistic care}

Provision of holistic care is at the foundation of any parish nurse program. Parish nurses provide holistic health care that is designed to treat and heal the entire person. Parish nurses practice holistic medicine by promoting healing and 
wholeness ${ }^{[4]}$. Holistic medicine has been defined by American Nurses Association \& Health Ministries Association in the book Scope and Standards of Faith Community Nursing ${ }^{[2]}$. In the book Holistic Nursing 2013 Scope and Standards of Practice co-published with the American Nurses Association, holistic nursing is defined as an official nursing specialty, and diverse activities undertaken by holistic nurses are described. Holistic nursing was described by Sharoff ${ }^{[7]}$ as a personal philosophy whereby nurses participate in the healing-caring process of self and others. At Westminster health ministries council nurses have studied the fundamental concepts of holistic medicine and base their care and activities on the philosophy of holistic care.

\section{Roles of parish nurses}

Parish nurses are registered nurses who typically have at least two years' experience as a working nurse. At WPC the congregation is very small, and nurses need only be licensed with one year minimum experience, with no experience in parish nursing required. As each nurse assumes a role in the health ministries council, orientation to the role and one-on-one mentoring is provided by nurses who have many years of experience as parish nurses. Westminster parish nurses assume a variety of roles. Through the parish nurse program, the roles that parish nurses play have enhanced the spiritual, physical, and emotional health of the congregation.

Parish nurses are members of the pastoral team who provide spiritual guidance to individuals and families facing problems and crises. Parish nurses reach out to members in need, listening and offering comfort, encouragement and help. They act as counselors and advisors, providing health advice and personal emotional encouragement. They assist individuals and families in accessing important resources in the church and community. These range from physicians and chiropractors to nutrition specialists and education programs from pre-school to college.

Parish nurses act as educators, providing health-related information, and teaching and training members of the congregation. They offer educational classes on current relevant topics on physical health such as hypertension, diabetes and nutrition, as well as emotional health such as coping with illness, hospice care and stress, and spiritual health such as participation in remembrance services for members who are grieving. Parish nurses foster health promotion by offering health information on a variety of subjects through articles written for publication in the monthly bulletin. Another role of the parish nurse is that of holding classes and discussion groups for senior groups and well as youth groups, on topics from how to avoid getting winter flu, to gastrointestinal health. Nurses set up walking and exercise programs, and encourage participants to improve overall health and mobility by participating in these events.

Parish nurses act as advocates for their members' health. The parish nurses focus on programs to foster wellness, and work with parishioners to provide healthy snacks, screen blood pressure and blood sugar, and provide yearly flu shot clinics. Parish nurses make many referrals- to community agencies, to physicians for high blood pressure, and cancer support. Referrals are often made for individual and group counseling for coping with emotional needs after a death or loss or traumatic event. Parish nurses offer client advocacy and home and hospital visitation. Parish nurses often act as a representative to assist clients to obtain needed health-related services or to help them decipher information about medications, and recent complex diagnoses and chronic illnesses. Setter ${ }^{[6]}$ cites multiple studies that document the role of nurses in medication management specifically during the transition from hospital discharge to home, where confusion and medication errors often occur. Follow-up phone calls are assigned to one nurse each week, and clients are given the phone number of the nurse in the weekly bulletin to call if needed.

\section{Organization and responsibilities of a parish nurse council}

To accomplish holistic medicine at Westminster Presbyterian Church, a health ministries council was formed and has been in existence since 1999. The Council is comprised of a small number of nurses who are members of the congregation and 
relies on additional support from some nurses who are not members of the committee but are members of the congregation. The council works in collaboration with the pastor and other committee members to formulate goals and plans. The council has outlined an array of opportunities and activities that are organized and provided each year to enhance healthy living. The nurses meet approximately six times a year on Saturdays for approximately two hours. The chair prepares the agenda and keeps track of the finances and follows up on program activities. Finances are limited and used to pay guest speakers, and purchase supplies and equipment. The funds are controlled by the council chair, and disbursed and overseen by the finance committee of the church. Parish nurses collaborate with several local health care facilities; Palomar-Pomerado Medical Center to conduct yearly flu shot clinics, and Redwood Terrace Skilled Nursing Center for elder activities, follow up, and referrals to long term care. The council nurses work collaboratively with the church pre-school to provide health information to parents. Meetings provide a time to reflect on responsibilities to the congregation, and meeting church members' needs. The meetings serve to help organize activities, and plan for screenings and education opportunities. The meetings are always started off with an inspirational message selected by the chair and a prayer to help guide the ministry. During the meetings, parishioners who have special health and spiritual needs are discussed, and nurses assume some responsibility for follow up and phone calls, or writing and sending cards for get well and condolence to them, and collaborating with the prayer team when the member has given permission.

Activities are focused on 1) identifying client health concerns, 2) establishing monthly and yearly health screenings, 3) planning for spiritual care of grieving families, and 4) organizing activities to promote healthy lifestyles and are demonstrated as follows: 1) When identifying client health concerns, discussions are strictly private confidentiality is afforded regarding patients' health and life situations. For example, parish nurses discuss clients who have been recently hospitalized, are undergoing tests and surgery, or experiencing chronic illness or injury. Suggestions are made to address these issues. When a member has recently undergone surgery, one of the parish nurses takes the call and reaches out to make contact and assess the patient's needs and whether the healing process is proceeding without complications. Two of the members recently had fractured femurs and required skilled nursing care, and referrals were made to an appropriate home care agency. Several elderly men and women have recently lost their spouses and are struggling to cope and maintain their independence and ability to care for their homes and health as a result. Some members have recently been diagnosed with depression and are followed with phone calls and cards. Many of the parishioners have limited mobility and find it difficult to get to services. Plans are made to encourage attendance at elder luncheons and to facilitate rides to and from events. Sometimes visits are made to the hospital or homes to assess the status of members having health issues. 2) Screenings are an important part of the ministry responsibilities. Yearly flu shot clinics are held in cooperation with Palomar-Pomerado Medical Center nurses and clients are strongly encouraged to obtain a vaccine. Those who cannot afford the cost are provided the vaccine for free. The clinics offer vaccinations to over 50 people in the fall of each year. Between services approximately five times per year blood pressure screenings are held, with resource tables containing blood pressure information and health and safety information and a nurse available for questions and support. Blood glucose clinics have been held as well, where information regarding diabetes and blood glucose is offered. Nutrition pamphlets and information are available each week, and a nurse is available between services to council families on nutrition and healthy eating. 3) To provide spiritual support and care for grieving families, parish nurses reach out by phone and home visits. Listening helps clients with the healing process and provides a caring and objective ear outside of the often burdened family realm. Sympathy cards are mailed to families who have experienced not only a recent loss, but past losses. Grief is often more pronounced at times of anniversaries, birthdays and other events, and outreach helps to improve their ability to cope with their loss. Parish nurses work together with other committees who provide quilts that have been sewn especially for families in bereavement. A service of remembrance is held once a year for families who are grieving the loss of loved ones. The services are led by the church pastor, with coordination from church staff, and the Health Ministries Council parish nurses. The services involve readings, candle lighting and a time for reflection and reliving memories by those who attend. Parishioners have given feedback that this service is one of the coping methods that helped in their bereavement the most. 4) Promotion of healthy lifestyles is accomplished through monthly articles and newsletters written by the nurses for the bulletin called "West Pres" highlighting health issues and available services. Some of the topics have included current issues of importance to both young and old, including infectious diseases, stress 
effects, urinary health, vaccinations for young and old, advance directives, polypharmacy, pain medications, and diabetes type II. Several times a year the council nurses organize and prepare a "Healthy Snacks" event during coffee hour with recipes available for healthy eating education. Each spring the council sponsors a walking program and nurses encourage members to participate in a collective walking event. Healthy "Cardio" yoga and "Holy" yoga classes are sponsored, with both traditional and chair yoga offered for elderly who can participate in the activities from a chair. The yoga classes have been successful, and additional classes were needed after only a few sessions. The council nurses collaborate with the preschool staff and parents and the youth groups to support and provide health education and classes on topics that include avoiding colds, nutrition for preschoolers, and vaccination information. The council supports a senior enrichment program called "Second Half" for seniors to focus on living healthy "best second half lives".

\section{Benefits of parish nursing}

There are some very tangible benefits of parish nursing. Parish nurses are in a unique position to meet each patient's spiritual, physical and emotional needs. Hilary Howard ${ }^{[3]}$ stated that parish nurses are in a good position to meet the spiritual needs of those who may find peace through a relationship with God. She describes a project of compassion undertaken by parish nurses where handmade blankets were designed and presented to loved ones of a deceased family member. At WPC this tradition is followed using homemade quilts offered at end-of-life. In end of life care, known as Hospice or Palliative care, peace with the dying process is paramount to experiencing a good death. Most of the parish nurses at Westminster know that spirituality has a big impact on not only end-of-life experiences but on health and healing. In the hospital setting things proceed with an extremely rapid pace, and decisions are made and treatments are given quickly, often to save a life. Prayer is often overlooked in the urgency of the moment. Despite this, it is becoming increasingly more common to see prayer between health care professionals and clients, and research and discussion on prayer and its effect on healing is a growing trend. Matthew 17:20 says "if you have faith nothing shall be impossible". This use of spiritual healing between parish nurses and clients during a health crisis is a powerful technique to empower oneself or to lighten another's load. Members benefit directly by the spiritual counseling that the health ministries council provides. At Westminster nurses gather information about faith needs and report to the committee where a plan is made to assess spiritual needs and provide spiritual care. The committee works in conjunction with the pastor and offers suggestions and referrals for pastoral services. The pastor is an integral part of the committee as a resource person and leader and is able to follow up with spiritual needs of the parishioners. Parish nurses assess a patient's spiritual support and even pray with patients confronted with a terminal illness. Families who have been supported through the end-of-life have articulated the satisfaction with the support they have received through their relationship with the health ministries council parish nurses. Both spiritual and scientific literature is available on the power of prayer in healing the injured and sick. Many nurses ask themselves if religious faith is a factor in healing. Research is increasingly revealing that physicians, skeptical for so long after being educated in the medical model, now believe in the power of prayer to enhance healing. Stories about miracles and the power of prayer in healing abound. Dr. Norman Vincent Peale ${ }^{[5]}$ describes story after story in his enduring inspirational book "The Power of Positive Thinking" in a chapter titled "How to Use Faith in Healing”. He describes how people he knew were healed through faith that had insurmountable cases of cancer and other illnesses. In each of these cases, either the person depended on faith to heal him or her, or practices by others that impacted the healing process. There is a growing emphasis on the amazing power of spiritual healing; in fact for centuries religion carried out healing activities, despite the lack of scientific basis for many cures and treatments. At WPC parish nursing benefits the participating nurses as well in a perceptible way. Meetings include a spiritual component and nurses come away with a feeling of having planned for good and been in sisterhood with one another.

In addition to spiritual health, the physical and emotional health of the congregation is improved by this program. For example, typically 30 blood pressures are obtained in a given month, and up to four or five are high enough to warrant referral to the physician. The same holds true for blood sugars. Of the 20 blood sugars taken in a month, at least two were referred for follow up. In some instances, patients have been counseled about medication dosages that were newly prescribed, sometimes being taken incorrectly as identified by the parish nurse. Members have expressed much 
satisfaction with the program and its offerings. They express appreciation for the screenings and health related information. Some members have called the parish nurse who has written an article for the month and voiced their satisfaction with learning new things about their chronic condition or medications. Members have enjoyed yoga classes, the walking program, guest presentations and follow up visits.

\section{Conclusion}

The health ministries council program at Westminster Church has made a significant impact on the spiritual, physical, and emotional health of the congregation. Parish nurses play a significant role in enhancing the collective health of the congregation by providing spiritual care, fostering healthy lifestyles, providing health screenings, promoting education, and comforting ill, injured and hurting people and their bereaved loved ones. Parish nurses believe in the power of healing through spiritual means. There are untold numbers in the congregation who are suffering in mind and body. Just as God helps the brokenhearted and binds their wounds (Psalm 147:3), Parish nurses offer an approach to re-create wholeness and a stronger sense of well-being, even when an ailment cannot be cured. Parish nursing council contributions at Westminster Presbyterian Church have truly added to the richness of the lives of the community it serves.

\section{References}

[1] Holistic Nursing: Scope and Standards of Practice [Internet]. San Francisco: American Holistic Nurses Association; c2007[cited 2013 Oct 14]. Available from: http://www.ahna.org/About-Us/ANA-Specialty-Recognition

[2] Scope and Standards of Faith Community Nursing[Internet]. Silver Spring: American Nurses Association \& Health Ministries Association; c2005[cited 2013 Oct 15]. Available from: http://nursingworld.org/HomepageCategory/NursingInsider/Archive_1/2012-NI/Jan-2012-NI/Faith-Community-Nursing-ScopeStandards-of-Practice.html

[3] Howard H. Compassion in nursing practice. Primary Health Care. 2012, 22(4): 21-23. http://dx.doi.org/10.7748/phc2012.05.22.4.21.c9073

[4] King MA. Parish nursing: Holistic nursing care in faith communities. Holistic Nursing Practice. 2011; 309-315. PMid:22015341 http://dx.doi.org/10.1097/HNP.0b013e318232c5e0

[5] Peale NV. The power of positive thinking. New York: Fireside Simon \& Shuster; 1952. PMid:14933538

[6] Setter SM. Transitional care: Exploring the home healthcare nurse’s role in medication management. 2012 Jan; 30 (1): $19-26$.

[7] Sharoff L. The power of metaphors: Images of holistic nurses. Holistic Nursing Practice. 2009 Sept/Oct; 267-275. PMid:19713784 http://dx.doi.org/10.1097/HNP.0b013e3181b66c97 